\title{
Balancing import and export in development
}

\author{
Markus Affolter, ${ }^{1}$ Thomas Marty, and M. Alessandra Vigano \\ Biocenter, University of Basel, CH-4056 Basel, Switzerland
}

\section{From HOX cofactors to HOX "cofactor complexes"}

During the development of multicellular organisms, the Hox gene family is involved in axial specification of many different structures, ranging from the neural tube to the intestinal tract. Despite the molecular cloning of the first Hox genes in 1984 and finding that they all encode homeodomain-containing transcriptional regulators, there is still little known about the mechanisms by which HOX proteins control gene expression and the nature of the downstream target genes that generate the morphological diversity.

Recently, three evolutionarily conserved classes of related homeobox genes that encode HOX cofactors have been identified (for a recent review, see Mann and Affolter 1998). The PBC proteins [in Drosophila encoded by extradenticle (exd), in vertebrates by the three pre- $B$ cell homeobox $(p b x)$ genes] can bind cooperatively with HOX proteins to a bipartite DNA sequence and modify the target selectivity, the binding affinity, and the regulatory activity of homeotic proteins. More recently, the PBC proteins themselves were shown to form stable heterodimeric complexes with proteins encoded by two related gene families, the prep and meis family [homothorax (hth) in Drosophila is a meis ortholog]. In contrast to the HOX-PBC interactions, which require binding of the proteins to DNA, the interaction of $\mathrm{PBC}$ proteins via the amino-terminal PBCA domain with PREP or MEIS proteins is highly efficient in solution in the absence of DNA. The functional association of HOX proteins with what appear to be extremely stable heterodimeric complexes of PBC and PREP/MEIS proteins has temporarily shifted interest from HOX proteins to these 'cofactor complexes' and the elucidation of their functional properties.

Several intriguing properties of PBC and PREP/MEIS proteins were discovered in genetic studies of the corresponding Drosophila orthologs exd and hth. Although first characterized as a HOX cofactor, it turned out that EXD also fulfills important functions in tissues devoid of canonical Hox gene products. For example, EXD activity is required for antennal determination (Gonzalez-Crespo and Morata 1995; Casares and Mann 1998). To exert

\footnotetext{
${ }^{1}$ Corresponding author.

E-MAIL affolter@ubaclu.unibas.ch; FAX 41-61-267-2078.
}

these functions, exd requires the function of HTH. It turns out that EXD activity is regulated post-translationally by a nuclear translocation mechanism: In the absence of HTH, the ubiquitously expressed EXD remains in the cytoplasm and is not functional. In the presence of $\mathrm{HTH}$, EXD translocates to the nucleus, a process that requires direct interaction between EXD and HTH (Rieckhof et al. 1997; Kurant et al. 1998; Pai et al. 1998 ). The finding that artificial nuclear localization of EXD at ectopic positions does not mimic the phenotypes observed in the presence of ectopic HTH (Casares and Mann 1998) strongly suggests that HTH is not only required for the nuclear localization of EXD but that HTH and EXD also function in a heterodimeric complex, presumably in the regulation of a distinct set of target genes. In Drosophila development, nuclear accumulation of the complex is spatially regulated in most cases by the transcription of $h t h$, resulting in regulated accumulation of HTH and, consequently, in nuclear import of EXD (Rieckhof et al. 1997).

\section{Controlled balance between import and export}

But how is the cytoplasm-to-nucleus translocation of EXD controlled by the presence of HTH protein? Two reports in this issue shed light on this question (AbuShaar et al. 1999; Berthelsen et al. 1999). Interestingly, the regulation of the intracellular localization of EXD or PBX1 proteins is accomplished by altering the balance of nuclear import versus nuclear export. The EXD and PBX1 proteins contain both a nuclear import signal (NLS) and a nuclear export signal (NES). The NES is required for the cytoplasmic localization of EXD/PBX1 in cells that lack HTH. The balance of import and export is tipped towards nuclear import by heterodimerization of EXD with HTH (or PBX1 with PREP1), mediated by amino-terminal conserved domains found in these two classes of proteins (the PBCA domain and the MH1 domain, respectively; Bürglin 1998). Both studies map a NLS to the homeodomain portion of the PBC protein (EXD or PBX1). However, the part of the proteins to which the putative NES was mapped differs. Abu-Shaar et al. (1999) report that the PBCB domain, a region of $\sim 90$ amino acids located between PBCA and the homeodomain and conserved among PBC family members, is responsible for EXD's cytoplasmic localization in Dro- 
sophila imaginal disc cells and in tissue culture. These investigators propose that HTH binding to EXD may induce a conformational change in EXD that alters the nuclear export/import balance by inactivating the NES, thus favoring nuclear import. Berthelsen et al. (1999) find that the sequences in PBX1 that act as NES in Drosophila tissue culture overlap the sequences in the PBCA domain that are essential for the interaction of PBX1 with PREP (or HTH). Therefore, these workers propose that heterodimerization with HTH and PREP induces nuclear translocation of EXD and PBX1, respectively, by directly blocking the NES.

The precise sequence requirements and the mechanism responsible for regulated nuclear export of $\mathrm{PBC}$ proteins will have to be investigated further: A critical criterion for an NES is its direct interaction with the export machinery. However, these studies show that altering the balance of export and import of a protein (EXD) through heterodimerization with a developmentally regulated factor $(\mathrm{HTH})$ is a novel and powerful mechanism to accumulate precise stoichiometric amounts of two proteins in the nucleus of specific cells. Indeed, during the development of appendages in the developing fly, the precise spatial regulation of the distribution of $\mathrm{HTH}-$ EXD complexes in the nucleus is clearly very important (Abu-Shaar and Mann 1998; Casares and Mann 1998).

\section{What does this all mean for the function of homeotic genes?}

Does the distribution of nuclear EXD-HTH complexes as it changes during ontogeny contribute to the functional diversity of HOX proteins? In other words, is HOX activity in certain tissues regulated indirectly via the control of the import/export balance of the cofactor complexes? Clearly, some HOX functions do not require EXD (Peifer and Wieschaus 1990; Rauskolb and Wieschaus 1994; Pinsonneault et al. 1997; Percival-Smith and Hayden 1998). In Drosophila, the development of the haltere, for example, is under the control of the homeotic gene Ultrabithorax $(U b x)$. Haltere development does not require exd, consistent with the finding that EXD protein is cytoplasmic and inactive in the center of the haltere imaginal disc (Azpiazu and Morata 1998). It is likely that the expression of specific UBXregulated genes may be directly perturbed by the presence of nuclear EXD-HTH complexes in the haltere field. Thus, we expect that the developmental specificity of HOX function is linked tightly to the spatial regulation and function of the cofactor complexes. It is also possible that the export/import balance of $\mathrm{PBC}$ proteins is regulated at the post-translational level in certain cells, for example by cell-cell signaling, thereby influencing the function of HOX proteins (Mann and AbuShaar 1996). Clearly, studies on the molecular function of HOX proteins have to be paralleled by a detailed analysis of cofactor requirements.

Very recently, the structures of the UBX-EXD and HOXB1-PBX1 DNA complexes were published (Passner et al. 1999; Piper et al. 1999). In these complexes, all of the homeodomains fold into the characteristic three $\alpha$ helix-containing globular domains. While the two homeodomains bind to opposite sides of the DNA, the conserved hexapeptide amino terminal to the HOX homeodomain inserts into a hydrophobic pocket on the PBC homeodomain. This pocket is created partly by a tripeptide loop that is characteristic for the PBC class of homeodomains. The use of these evolutionarily conserved features in HOX and $\mathrm{PBC}$ proteins for cooperative DNA binding suggests a strong selective pressure favoring these particular intermolecular interactions. However, the stable heterodimer formation between $\mathrm{PBC}$ proteins and PREP/MEIS proteins suggests that in all cases a third homeodomain is linked physically in vivo to the dimeric HOX-PBC complexes. The presence of the characteristic tripeptide loop in the PREP/MEIS homeodomains further suggests the possibility that such a HOXPBC-PREP/MEIS triple complex interacts on DNA with yet another HOX or HOX-related protein that inserts the hexapeptide into the predicted pocket in the PREP/MEIS component (Shen et al. 1997; Kroon et al. 1998; Swift et al. 1998). Clearly, more and more partners are joining the HOX proteins.

But do all these proteins contribute to HOX function? So far, the formation of triple complexes has only been reported in DNA binding assays in vitro (Berthelsen et al. 1998b). In cell culture experiments, it has been shown that PREP1 is able to regulate positively the transcriptional activity of the HOXB1-PBX1 complex on the Hoxb-1 autoregulatory element (Berthelsen et al. 1998b). The available structures allow the design of specific mutations in interaction surfaces (e.g., the binding pocket) of PBC or PREP/MEIS proteins and the analysis of their effect on cis-acting elements known to be direct targets in vivo (Pöpperl et al. 1995; Grieder et al. 1997). Similarly, the effect of hexapeptide mutations in vivo on well defined targets will allow the investigation of the function of HOX proteins in the absence of cooperativity. By analogy, mutations in the homeodomains that abolish DNA binding might also shed light on the composition of the complex on in vivo targets. Despite the increasing complexity of these homeoprotein-containing regulatory complexes, characterization of these complexes will eventually help to elucidate the molecular mechanisms underlying the exquisite control of morphological diversity by Hox genes during animal development.

\section{Acknowledgments}

We thank Anthony Percival-Smith for helpful discussions.

\section{References}

Abu-Shaar, M. and R.S. Mann. 1998. Generation of multiple antagonistic domains along the proximodistal axis during Drosophila leg development. Development 125: 3821-3830.

Abu-Shaar, M., H.D. Ryoo, and R.S. Mann. 1999. Control of the nuclear localization of Extradenticle by competing nuclear import and export signals. Genes \& Dev. (this issue).

Azpiazu, N. and G. Morata. 1998. Functional and regulatory interactions between Hox and extradenticle genes. Genes \& 
Dev. 12: 261-273.

Berthelsen, J., V. Zappavigna, F. Mavilio, and F. Blasi. 1998a. Prep1, a novel functional partner of Pbx proteins. EMBO $J$. 17: 1423-1433.

Berthelsen, J., V. Zappavigna, E. Ferretti, F. Mavilio, and F. Blasi. 1998b. The novel homeoprotein Prep1 modulates Pbx-Hox protein cooperativity. EMBO J. 17: 1434-1445.

Berthelsen, J., C. Kilstrup-Nielsen, F. Blasi, F. Mavilio, and V. Zappavigna. 1999. The subcellular localization of PBX1 and EXD proteins depends on nuclear import and export signals and is modulated by association with PREP1 and HTH. Genes \& Dev. (this issue).

Bürglin, T.R. 1997. Analysis of TALE superclass homeobox genes (MEIS, PBC, KNOX, Iroquois, TGIF) reveals a novel domain conserved between plants and animals. Nucleic Acids Res. 25: 4173-4180.

Casares, F. and R.S. Mann. 1998. Control of antennal versus leg development in Drosophila. Nature 392: 723-726.

Chang, C.-P., Y. Jacobs, T. Nakamura, N.A. Jenkins, N.G. Copeland, and M.L. Cleary. 1997. Meis proteins are major in vivo DNA binding partners for wild type but not chimeric Pbx proteins. Mol. Cell. Biol. 17: 5679-5687.

Gonzalez-Crespo, S. and G. Morata. 1995. Control of Drosophila adult pattern by extradenticle. Development 121: $2117-2125$.

Gonzales-Crespo, S., M. Abu-Shaar, M. Torres, C. MartinezArias, R.S. Mann, and G. Morata. 1998. Antagonism between Extradenticle function and Hedgehog signalling in the developing limb. Nature 394: 196-199.

Grieder, N., T. Marty, H.D. Ryoo, R.S. Mann, and M. Affolter. 1997. Synergistic activation of a Drosophila enhancer by HOM/EXD and DPP signaling. EMBO J. 16: 7402-7410.

Kroon, E., J. Kros, U. Thorsteinsdottir, S. Baban, A.M. Buchberg, and G. Sauvageau. 1998. Hoxa9 transforms primary bone marrow cells through specific collaboration with Meis1a but not $P b x 1 b . E M B O ~ T . ~ 17: 3714-3725$.

Kurant, E., C.-Y. Pai, R. Sharf, N. Halachmi, Y.H. Sun, and A. Salzberg. 1998. Dorsotonals/homothorax, the Drosophila homologue of meis1, interacts with extradenticle in patterning of the embryonic PNS. Development 125: 1037-1048.

Mann, R.S. and M. Abu-Shaar. 1996. Nuclear import of the homeodomain protein Extradenticle in response to Wg and Dpp signalling. Nature 383: 630-633.

Mann, R.S. and M. Affolter. 1998. Hox proteins meet more partners. Curr. Opin. Genet. Dev. 8: 423-429.

Pai, C.-Y., T.-S. Kuo, T.J. Jaw, E. Kurant, C.-T. Chen, D.A. Bessarab, A. Salzberg, and Y.H. Sun. 1998. The Homothorax homeoprotein activates the nuclear localization of another homeoprotein, Extradenticle, and suppresses eye development in Drosophila. Genes \& Dev. 12: 435-446.

Passner, J.M., H.D. Ryoo, L. Shen, R.S. Mann, and A.K. Aggarwal. 1999. Structure of a DNA-bound Ultrabithorax-Extradenticle homeodomain complex. Nature 397: 714-719.

Peifer, M. and E. Wieschaus. 1990. Mutations in the Drosophila gene extradenticle affect the way specific homeo domain proteins regulate segmental identity. Genes \& Dev. 4: 12091223.

Percival-Smith, A. and D.J. Hayden. 1998. Analysis in Drosophila melanogaster of the interaction between Sex Combs Reduced and Extradenticle activity in the determination of tarsus and arista identity. Genetics 150: 189-198.

Pinsonneault, J., B. Florence, H. Vaessin, and W. McGinnis. 1997. A model for extradenticle function as a switch that changes HOX proteins from repressors to activators. $E M B O$ J. 16: 2032-2042.

Piper, D.E., A.H. Batchelor, C.-P. Chang, M.L. Cleary, and C.
Wolberger. 1999. Structure of a HoxB1-Pbx1 heterodimer bound to DNA: Role of the hexapeptide and a fourth homeodomain helix in complex formation. Cell 96: 587-597.

Pöpperl, H., M. Bienz, M. Studer, S.K. Chan, S. Aparicio, S. Brenner, R.S. Mann, and R. Krumlauf. 1995. Segmental expression of $H o x b-1$ is controlled by a highly conserved autoregulatory loop dependent upon exd/Pbx. Cell 81: 10311042.

Rauskolb, C. and E. Wieschaus. 1994. Coordinate regulation of downstream genes by extradenticle and the selector proteins. EMBO T. 13: 3561-3569.

Rieckhof, G.E., F. Casares, H.D. Ryoo, M. Abu-Shaar, and R.S. Mann. 1997. Nuclear translocation of extradenticle requires homothorax, which encodes an extradenticle-related homeodomain protein. Cell 91: 171-183.

Shen, W.F., J.C. Montgomery, S. Rozenfeld, J.J. Moskow, H.J. Lawrence, A.M. Buchberg, and C. Largman. 1997. AbdB-like Hox proteins stabilize DNA binding by the Meis1 homeodomain proteins. Mol. Cell. Biol. 17: 6448-6458.

Swift, G.H., Y. Liu, S.D. Rose, L.J. Bischof, S. Steelman, A.M. Buchberg, C.V.E. Wright, and R.J. MacDonald. 1998. An endocrine-exocrine switch in the activity of the pancreatic homeodomain protein PDX1 through formation of a trimeric complex with PBX1b and MRG1 (MEIS2). Mol. Cell. Biol. 18: $5109-5120$. 


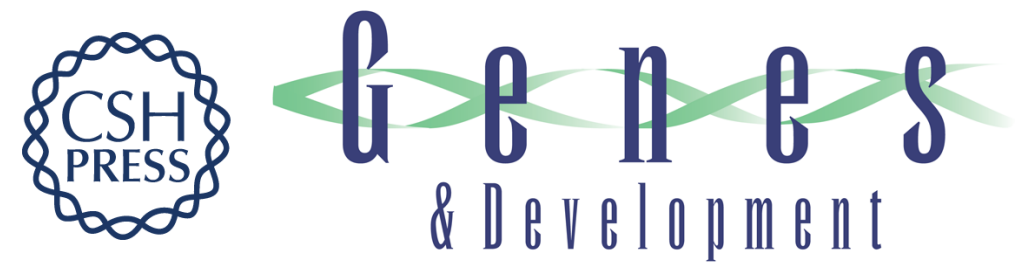

\section{Balancing import and export in development}

Markus Affolter, Thomas Marty and M. Alessandra Vigano

Genes Dev. 1999, 13:

References This article cites 25 articles, 15 of which can be accessed free at: http://genesdev.cshlp.org/content/13/8/913.full.html\#ref-list-1

License

Email Alerting

Receive free email alerts when new articles cite this article - sign up in the box at the top Service right corner of the article or click here.

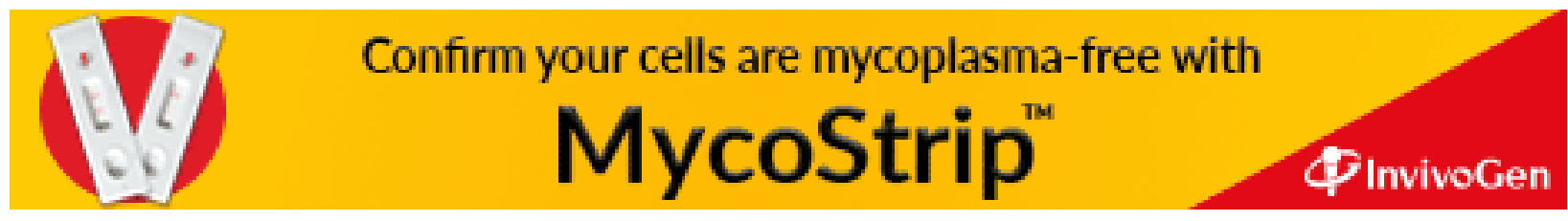

